\title{
Reducing cognitive load in multimedia navigation
}

\author{
John G Hedberg, Barry Harper and Christine Brown \\ University of Wollongong
}

\begin{abstract}
The emergence of integrated technologies is facilitating the configuration of vision and sound in ways previously impossible with discrete technologies. The attributes of infinite storage, continually increasing speed of access and phenomenal manipulation of images and sound are moving rapidly towards the notion of virtual reality in technology based information and presentation systems. What are the implications for instructional design? This paper discusses effective multimedia design strategies which results in the creation of multimedia programs. Implications for the development of materials with groups located at geographically different places are discussed. This impacts on the possibility of developing multimedia material between different groups in different countries.
\end{abstract}

Navigation is a unique problem for the interactive multimedia environment - the user must browse information often with a number of options and choices. These options are cued by a number of different devices. Navigation can take a series of forms: it can allow increased learner control, by indicating learning options; it can provide a physical model of either the learning sequence or the layout of the information; or it can be adapted to meet the learner's requirements and even allow the user to specify the relationships he or she wishes for the information. Information in a multimedia environment can include any form of representation: text, graphic, picture, sound, animation or motion video. These options increase the difficulty in organising information by the learner. Faced with a multitude of possible choices, inputs and paths through information landscapes, a learner can easily become confused and a powerful vehicle for learning can become a time consuming problem. This paper reports on a study of the navigational demands of hierarchical, 
relational and sequential navigation systems in interactive multimedia learning materials and discusses the instructional design implications for learner generated and instructor generated interactive multimedia materials.

\section{Background}

Considerable interest in the educational efficacy of the application of interactive multimedia resources for learning has developed as the use of this technology has emerged. A number of interactive multimedia simulation packages have been developed to incorporate high quality visual materials in the form of graphics, pictures, sound, animation or motion video. Some of the packages are prototypes and we are now starting to see some commercial products produced and released on the market. This major growth in the application and use of interactive multimedia resources for learning has occurred through changes in information technology software and hardware which allow the integration of multiple sources of information to be linked and presented together (Ambron \& Hooper, 1990). This development has occurred coincidentally with the proliferation of sophisticated software authoring tools, which have not only given educators greater access to the production and design of learning packages but also enabled information to be structured in new ways which allow the simulation of a greater variety of learning models (Hedberg \& Harper, 1992a).

This rapid technological development necessitates a closer examination of the ways in which information is accessed and the concept of an information landscape has been introduced into the literature to indicate that this information can be represented and retrieved in a number of ways and in a variety of forms. It has allowed new and more complex instructional strategies to be employed in instructional software which offer the potential of more efficient and effective learning. While these learning strategies can be controlled by the learner and can employ a variety of cognitive modelling opportunities to facilitate learning (Hedberg, 1989), research on the efficacy on the variety of information access systems is lagging behind the technological developments.

With interactive multimedia the potential to shift the control of learning from the instructor, either as the teacher or through computer control and management, to the learner has been an important theme for many authors. Bork (1991) has supported the use of the media for studentcentred applications as opposed to administrative-centred or teachercentred applications with this form of learning strategy a recurring theme throughout modern pre-tertiary curriculum documents. Current technologies facilitate the use of such materials by individuals and small groups and challenge instructional designers to develop educational 
systems to take full advantage of the interactivity not simply in terms of user control but to enable users to actively chose their learning strategy.

As the use of this technology has developed the concept of user control has become an important and essential issue. There needs to be consideration of how much user control over learning strategies is the most efficient. Hedberg and Perry (1985) have proposed that used effectively, the technology can allow users to interact in ways that the designers of the system did not plan and that good instructional design of interactive multimedia materials makes it unnecessary for materials to be structured for the learner. Effective student use of unstructured materials, however, will depend on the type of access to the information the user can obtain: that is, the navigation options available to the user.

\section{Navigation Systems and Learning}

There are a number of problems with the existing research on navigation systems, including:

- the need to investigate the cognitive demands of different navigation systems in interactive multimedia learning materials;

- the extent to which current interactive multimedia design models address the issue of navigation;

- the importance of navigation in achieving improved learning outcomes; and

- the efficiency of navigation systems in giving control to the learner both in learning options and in cognitive development.

An understanding of the theoretical issues raised by navigation systems can support the growing development of intelligent interactive teaching environments. The complex integration now possible with this variety of hardware and software combinations raises problems for the user in that multiple paths arc possible to the same or different-end points. Learners are faced with the problem of understanding what learning possibilities might be available from where they are in a multimedia learning environment. When a student can branch down multiple paths and rapidly change the direction and focus of the learning sequence, there is possible interference with effective learning through the inappropriate application of information by the learner to their internal schemata.

\section{Cognition and metacognition as a basis for navigation}

Paris \& Winograd (1990) have defined metacognition as knowledge about cognitive states and abilities that can be shared among individuals, including the affective and motivational aspects of thinking. It is about cognitive self appraisal (how people act on what they say is important) and 
self-management of cognition (what people say they will do and their actions). Cognitive Self-Appraisal can be declarative (what), procedural (how you think) and conditional (when and how you think). Cognitive Self-Management is the way metacognition helps to orchestrate cognitive aspects of problem solving. Students form good plans, use a variety of strategies and monitor and revise ongoing performance. In short they are evaluating, planning and regulating. Metacognition should be regarded as an intermediate step to proficiency, embedded in ongoing thinking and problem-solving. It is particularly important for new knowledge mastery, trouble shooting with awareness of strategies, and initial teaching of skills. The metaphor of cognitive tools is consistent with the ideas of Vygotsky (1978). Good craftsmen use tools wisely and independently. Self-appraisal is not devoid of affect. Many decisions are underpinned by how students feel. You can't separate motivational aspects from cognitive knowledge.

The term metacognition is used freely in the literature but often without a clear understanding of its meaning (Alexander, Schallert, \& Hare, 1991). Metacognitive knowledge is a theoretical construct with four sub components:

Self-knowledge or perceptions of yourself as a learner, what you do best or worst, how you compare yourself with others.

Task knowledge of the types of cognitive tasks encountered.

Strategic knowledge of both cognitive and metacognitive strategies. Cognitive strategies are the processes or procedures which may need to be initiated to prompt better learning or thinking. Metacognitive strategies are self checking procedures which monitor how well the cognitive strategy worked.

Plans or Goals are what guide the learning process and encompass the affective understandings that learners have about themselves and in relation to others. Judgements and decisions are aligned to goals or plans learners establish. The influence of motivation on cognition is acknowledged.

This supports the definition of Paris and Winograd in all but the shared aspect. Others view metacognition as a procedural skill, with alternate names such as self- regulation, autonomous learning, and meta-reasoning (Eylon \& Linn, 1988), as a link with Schema Theory (Anstey, 1988) or incorporating metamemory, metacomprehension, self-regulation, schema training and transfer (Osman \& Hannafin, 1992).

Metamemory includes awareness of different memory strategies and when and how to use them. 
Metacomprehension is knowing about comprehension and how to comprehend. Comprehension failure must be recognised and repair strategies implemented.

Self-Regulation is continuous metacognitive adjustments by learners in response to feedback on errors. It is not good for the learner to rely solely on external prompts - they should learn self-sufficiency.

Schema Training involves the construction of conceptual frameworks which assist comprehension.

Transfer is the application of a strategy to dissimilar tasks, problems or circumstances. Transfer is near if the problem is similar, to far if the problem is dissimilar. Another terminology refers to "low-road" transfer as detail and low-level knowledge, while "high-road" transfer emphasises relational, conceptual knowledge.

Early research on metacognition was correlational research connecting what learners knew about memory processes and subsequent performance. Theory expanded to view components of metamemory such as specific strategy knowledge, Metamemory Acquisition Procedures (MAPS) which were strategies that operate on other strategies and require deliberate self-reflection, and general strategy knowledge. Learners who feel good about themselves and their ability - who are intrinsically motivated to learn and who have effort-related attributions - are more likely to believe in strategic behaviour and to develop complex, mature strategy knowledge. External control attributional beliefs undermine intrinsic motivation. Self constructs power metacognition by giving learners reasons to learn. Effort related attributions are of little use if learners "spin their wheels", not knowing the strategies to proceed. Hence self and metacognitive systems have to be supported together, to maximise their performance.

If we are viewing metacognition as something each of us has in a measurable dose, something that reflects our ability to learn and something which can be used to predict our future performance, then the construct is of little value. Rather, metacognition is about knowledge, skills, judgements of task difficulty and effort, beliefs about ability, worth of strategies, use of failure and purpose for performing tasks. All these guide learner decisions on task choice, the effort they will expend and the strategies chosen (Paris \& Winograd, 1990). In these ways metacognition, a multidimensional construct, firmly underpins learning. Metacognitive support should be affective, motivational and strategy-based, its goal the improvement of learning generally.

The concept has some persistent problems which must be acknowledged. It has a fuzzy definition - can metacognition occur unconsciously or must 
it be conscious? Even if we felt confident of measuring a component of metacognitive knowledge, there are considerable differences between novices and experts in their strategy use which would confound comparison. The construct can't have explanatory power and we can't prescribe techniques if we don't understand exactly how it helps learning (Paris \& Winograd, 1990). Likewise it does not have any predictive value. A successful manager in one domain of knowledge is frequently transferred or promoted to another domain. The underlying assumption is that the problem-solving strategies exhibited in the first instance will automatically transfer to the second domain. While it is beneficial to learn a range of concepts within one context or knowledge domain (Bransford, Vye, Kinzer, \& Risko, 1990), this does not mean that all those concepts will be transferred to the new situation with equal success. Does this mean the new manager "rises from the ranks of the knowledge domain", or is he/she best found elsewhere? There is no easy answer. Every person and situation is unique, due to the multiplicity of variables.

A conceptual framework of knowledge has two major planes - conceptual knowledge and metacognitive knowledge, which we have already discussed. Whatever its type, knowledge has three distinct forms, as referred to in self- appraisal: declarative, procedural and conditional. The acquisition of knowledge in one form doesn't automatically guarantee another form. In many instances we know the "what" without the "how" and "when" (Alexander et al., 1991).

One needs specific knowledge to solve problems, but in addition that knowledge must be spontaneously accessible, not inert. Frequently, people need to be reminded of what they already know. They can supply facts on demand, but this doesn't guarantee their spontaneous use in problem solving. Knowledge of general strategies can remain inert unless people are specifically prompted to try them. With conditional knowledge, when to use it is stored with the knowledge (Bransford et al., 1990).

Motivation is a key component of metacognition. If students select not to learn then that is that. In an analysis of what high school students found motivating in science experiments, Martinez and Haertel (1991) suggested that to the extent science experiments could be made cognitively challenging, they would engage the interest of students. Higher-Order Thinking Skills (HOTS) are now being encouraged in principle (Lawrenz, 1990) if not in uniform practice.

The problem-solving approach to learning relies on specific knowledge schemata which are available to the expert, but not the novice. If problem solving is used as a technique for acquiring a schema, it has been suggested that some forms of problem-solving can interfere due to the cognitive load of the problem-solving mechanism (Sweller, 1988). 
Problem-solving in this context would not support schema formation. The need for the basic knowledge has not gone - it must underpin the problemsolving approach to learning.

Transfer of knowledge to the solution of "real life" problems is the ultimate goal of education. The "how" of transfer (mechanisms that lead to it) has been separated from the "what" of transfer (the kind of knowledge and skill that might get transferred) (Salomon \& Perkins, 1989) to explain some seeming inconsistencies in research findings. Low-road transfer depends on extensive, varied practice and is automatically triggered in a new context. High-road transfer occurs by intentional mindful abstraction from one context and application in another context. Relevance of material is a necessary but not sufficient indicator of transfer.

It seems the current focus is on higher-order thinking, problem-solving and transfer. Concurrent developments in technology have added another level of complexity to the issue. Rather than compounding concerns, this technology may offer some unique solutions.

\section{The Constructivist-Objectivist Controversy}

At the peak of the 1991 controversy, which will no doubt continue to simmer, this quote typified the frustration and emotion of the issue:

Is it any wonder that constructivism is so much in vogue in academe? It can mean whatever the speaker wishes it to mean - a very nice example of subjectivism! (Molenda, 1991).

David Merrill (1991) strongly defended his ID2 model, supported and praised the moderate constructivist views and expressed the feeling that ID2 could do well to support these task relevant, action and experiential learning environments. He did not support the views of extreme constructivists. Perkins (1991a) characterised five facets of the learning environment, expressing the view that constructivist environments and ID2 could both support an increase in construction kits and phenomenaria. His fence sitting was a source of annoyance for some (Molenda, 1991). Constructivists were identified as WIG (without instruction given) or BIG (beyond instruction given) in their approach. The former were characterised by their total lack of use of any direct instruction and reliance on the learner "rediscovering" everything for themself.

According to Winn (1991) emphasis on instruction and performance had served well for teaching basic knowledge and skills but in the mastery of advanced knowledge in ill-structured domains, a different conception of instructional strategy seemed necessary. Constructivists de-emphasise instruction and performance and place far more responsibility for deciding what and how to learn on the student. The instructor or instructional 
system is there to support the student decision. The technology used to promote learning as opposed to instruction has been described as "empty" - the software are "shells" that accept any content that allows students to explore and construct meaning for themselves. They function as tools that students use to develop cognitive skills.

Hypertext knowledge bases typically are structured to reflect the organisation of knowledge or the content domain, whereas instructional design systems are designed to reflect a task (learning outcome) functionality Jonassen, 1991b). Hypertext can function as a model of schema theory. By modelling an expert's knowledge structure in the hypertext document, a useful knowledge structure may be mapped more directly onto the learner's cognitive structure. Jonassen offers hypertext systems as an alternative to ID2. He discussed the Instructional Design Environment (IDE), an interactive hypermedia system that designers can use to create courses by structuring the content and creating instructional sequences.

To the learner, the constructivist learning experience may not look welcoming (Perkins, 1991b). It may seem daunting and complex to those who feel ill-prepared for such creative freedom. Often constructivist learning situations suddenly throw students on their own management resources and many fend poorly in the high cognitive complexity of the learning environment. Cognitive support tools and the explicit acknowledgment of the double agenda of self-management and learning can help. The scaffolding and coaching in the cognitive apprenticeship model offer another solution.

Evaluation of constructivist learning emphasises higher-order thinking (Jonassen, 1991a). It focuses on the process within an authentic task rather than the product. Context driven and dependent, this evaluation accepts the likelihood of multiple perspectives, the possibility of a range of tasks, and the need to be evaluated by a panel of goal free examiners from a range of backgrounds. David Jonassen (1991a) recommends the most effective application of constructivist learning environments is to the stage of advanced knowledge acquisition, where students already have well formed schema and knowledge integration. Advanced knowledge must be gained in order to solve complex domain- or context- dependent problems.

\section{Metacognition in Instructional Design}

Metacognitive strategies can be effectively trained and transferred, but results are variable. The functions of the strategies vary with the way they are included in training. Strategies may be embedded within the lesson, or detached and taught separately They can be content-dependent, aimed at teaching specific lesson content, or content-independent, where they are 
applied across tasks or lessons. The classification matrix summarises the intended functions of these strategies:

Table 1: Classification Matrix for Metacognitive Strategies (after Osman \& Hannafin, 1992, p91)

\begin{tabular}{|l|l|l|}
\hline \multirow{2}{*}{$\begin{array}{l}\text { Training } \\
\text { Approach }\end{array}$} & \multicolumn{2}{|c|}{ Relationship To Learning Content } \\
\cline { 2 - 3 } & $\begin{array}{l}\text { Content Dependent } \\
\text { Strategy (CDS) }\end{array}$ & $\begin{array}{l}\text { Content Independent Strategy } \\
\text { (CIS) }\end{array}$ \\
\hline $\begin{array}{l}\text { Embedded } \\
\text { ECDS are specialised, task }\end{array}$ & $\begin{array}{l}\text { ECIS are general learning } \\
\text { specific strategies } \\
\text { applicable to particular } \\
\text { content. They are design } \\
\text { centred strategies that } \\
\text { available content to be learned. } \\
\text { emphasise near transfer. } \\
\text { These strategies support local } \\
\text { learning but emphasise strategy } \\
\text { transfer as well. }\end{array}$ \\
\hline $\begin{array}{l}\text { Detached } \\
\text { (D) }\end{array}$ & $\begin{array}{l}\text { DCDS are general learning } \\
\text { strategies that are taught } \\
\text { separately but } \\
\text { subsequently applied } \\
\text { within particular contexts. } \\
\text { DCDS usually promote } \\
\text { somewhat more transfer } \\
\text { than ECDS, but the goal is } \\
\text { typically to support a } \\
\text { particular lesson. }\end{array}$ & $\begin{array}{l}\text { strategies that have applications } \\
\text { across learning tasks. Both } \\
\text { learning content and contexts } \\
\text { are varied. Lesson content role } \\
\text { during training mainly to } \\
\text { provide representative range of } \\
\text { application. The emphasis is on } \\
\text { far transfer. }\end{array}$ \\
\hline
\end{tabular}

The design implications of metacognitive research on instructional design include the balance of strategies with the cognitive task, explicit instructions for younger learners and novices, a balance of complementary strategies and the provision of encouragement to learners to discuss the learning process. If the aim is far transfer of the strategy, then the metacognitive training should be detached and the lesson content varied. To assist "high road" transfer, connections outside the lesson content and integration of knowledge should be emphasised. Dependence on external cues for support should be avoided (Osman \& Hannafin, 1992).

\section{Instructional Design for Multimedia}

Squires and Millwood (1988) have reviewed the influence of new software forms (such as HyperCard) on the development of instructional packages. they found two common models of courseware development.

- The individual author approach where one person acts a as curriculum expert, content expert, programmer and instructional designer.

- The team approach which enables a division of labour by experts in each of the specialised areas. 
The team approach to courseware development has considerable advantage over individual authoring. Team development provides a rich environment within which various team members provide unique contributions. However, the development of high level general purpose programming languages and environments has empowered education/trainers with the tools to achieve sophisticated prototypes without relying on expert programmers. Most team projects rely on content experts developing the basic outline, an instructional designer taking the outline identifying the tasks and subtasks, and developing an instructional strategy which takes account of the structure of these learning tasks and the conceptual development requirements of the learner. The resultant detailed brief can then be "programmed" in an interactive prototyping approach where all four main contributors subject matter expert, instructional designer, graphics/interface designer and programmer combine to produce the first sets of materials.

The advantage of this approach is that the subject matter expert focuses on the accuracy of the content; the instructional designer focuses on the conceptual development and the match between instructional approach and the target audience; the graphics/interface designer assists with the visual concept and the integration between instructional strategy and its visual implementation; and the software programmer can also contribute, especially if a package has more than the combination of routine frames. This combination of skills allows each to focus on the matching of their elements to the ultimate objective.

An additional consideration is the languages of implementation have a structure which allows more common ground between members of the team. HyperCard's programming language, HyperTalk, is based upon "... cognitive models of how people learn in such a way that they make the environment of the computer available, relevant, rich and malleable to the user, ... HyperCard is fundamentally designed to address how people think .... We can now design pedagogical surrounds with tools designed to be compatible with mental activities." (Hooper, p7). It is with such tools that the traditional models for the design of computer based learning materials must become less compartmentalised and the cross-over between each specialist area becomes less clear.

To further add complexity to the development model, when each member of the team is located geographically at the same site their are possibilities for sharing of ideas formally and informally. There is no necessary constrain for these members to be so located and the possibilities of other combinations using electronic mail raises some exciting sharing of ideas and the processes through which they are translated into practical projects. 
The traditional model of instructional systems design indicates a sequential series of steps that dovetail into a final product. The outputs of each phase become the inputs to the next stage of the total process. The elements of the design phase are employed to organise the proposed objectives or goals of the process into some meaningful learning structure. This may include the organisation of materials in terms of facts, concepts, principles and procedures to lead to the development of higher-order problem solving skills. The myriad of proposals which assist the instructional designer do not really suggest mechanisms which provide the individual designer with sufficient information and structure to generate the more complex design brief required of interactive multimedia or hypermedia contexts.

The model described here has been employed in a variety of projects and is based on a more organic and iterative approach. In the design phase, three elements are considered. Phase one takes the basic information derived from a needs assessment and converts it into a description of the Project space - the information which is to be included in the materials, how it is structured, what the target audience understands about the information and how it might be structured for the audience. A possible structuring device might a concept map of the ideas and links that are to be included in the project.

The second phase reviews the basic description and seeks to link the elements through an appropriate instructional strategy and unifying metaphors which help both the design team and the final presentation of the information structure. The outcome of the second phase would be a formal description such as a design brief. The detail would enable the reader to understand the underlying knowledge structures and the ways it is proposed to link them conceptually and intuitively.

The third phase is a third pass at the same material, this time with the express goal of linking the design ideas into a potential interaction structure. One output of this phase would be an interactive mock-up of the interactive materials using such tools as HyperCard to illustrate not only static display of information but also the graphical and visual metaphors used to create understandable links. The information included in this prototype may include visual, motion, statics, sound and data landscapes as appropriate to the concept under development. Each interaction consists of a node point which forms the basis of the interaction, a set of options which provide links to other nodes or a set of additional pieces of information attached to the current node. One of the links must relate to earlier travelled or preferred paths through the materials, and each choice must inform the user about what is likely to occur as a result of a choice. These can translate into the traditional concept of results (correct or incorrect) or information feedback choice, but should also include simple 
feedback elements such as confirmation of choice (feedback that a button has been selected) or performance support enhancement such as suggested hints, or revision of the underlying concept / principle which might be employed to make the choice. Depending on the instructional strategy chosen another element might include the concept of duration, either time or the limit of options based upon previous choices or paths taken. What constitutes each of these functions and what they create in terms of cognitive skill development for the user are determined by their physical manifestation in terms of navigation options.

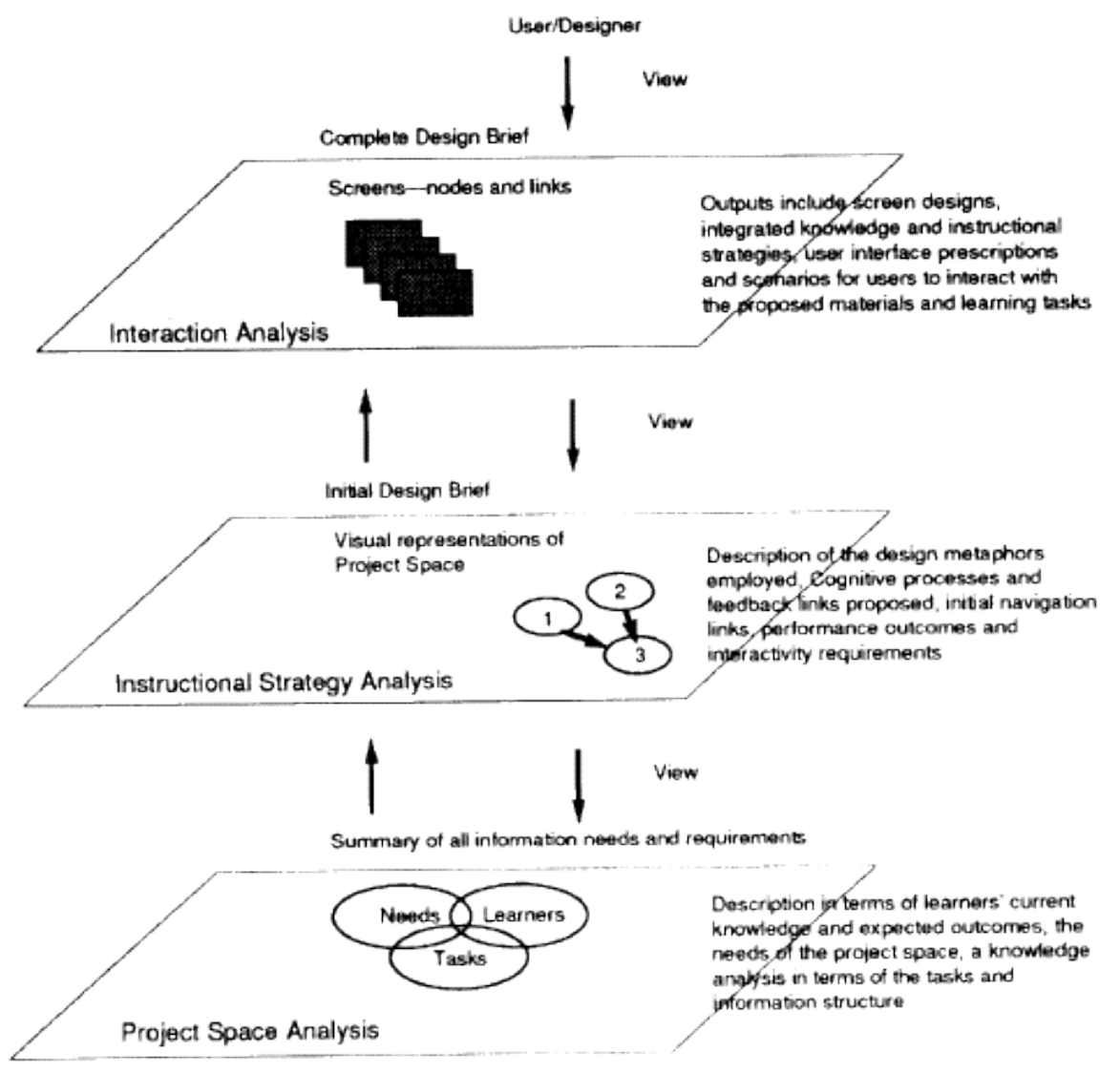

Figure 1: The instructional design process for deriving an interactive navigational system. 


\section{Navigation Options}

Navigation systems can facilitate the understanding of a students learning sequence and reduce the problems of poor learning schema development. A number of approaches have been discussed in the literature, such as the Guide metaphor where a character is created and used by the author to link ideas and visual travel through the hypermedia materials (Oren et al, 1990). Other suggested structures include those which are based on ideas such as sequential navigation (using cues to show how far you are along a path; the clues varying from a simple screen number of the total or some conceptual description of the sequence), visual navigation (using a plan of the possible paths), and hybrid navigation (mixtures of both) (Hedberg \& Harper, 1991).

Using the computer to model the knowledge base and to give the learner the freedom to interact with it gives autonomy back to the learner. Rather than give the learner a set of pre-designed learning sequences that assume some learning model, a more interactive approach could be developed by giving the user an information landscape and the tools necessary to explore and investigate the information. The change in locus of control from instructor to learner raises a series of hypermedia issues about cognition, motivation and navigation which need to be explored (Grabowski \& Curtis, 1991) and the outcomes applied to the current navigation systems. This is where the level of flexibility and adaptive nature of the navigation system is important.

Package designers have used a variety of techniques in screen design to present navigation cues for users. They include:

- using colour to identify the area or major learning path;

- the positioning of the element in the screen to indicate the place in relationship to the underlying metaphor (in this case a simulated lake) or the separation of positional navigation choices from the functional options (eg. separation of the movement from help and explanation functions);

- simple use of contextual clues, regular use of a standard format of basic word style format to indicate links with other sources of information;

- written directions which appear in separate areas or windows to the information required to learn the underlying concepts;

- simplified mnemonics or preferably the use of icons to provide standard and immediately comprehensible support for navigation or learning

- the development of search strategies and links to metaphorical maps which encapsulate learning path choices;

- enabling learning path maps to be modified highlighting the paths which have been travelled; creating new links by the learner using a series of tools which enable the package to be modified, either by 
adding new information or by adding new hypertext linkages based on the students own conceptual maps.

\section{Defining Navigation Types}

Research into the area of Cognitive Load Theory (Sweller, 1988) has demonstrated that materials can be designed to focus on the appropriate development of schema and hence improve learning efficiency. In effect any navigational system must employ elements with as much intrinsic meaning as possible. However, creating this link between action and meaning may not be as intuitive as designers sometimes assume, but this link can be enhanced through understandable and well chosen metaphors. Together with the growing emphasis on Constructivist approaches to the design of multimedia learning experiences, an alternative theoretical basis for considering the problem of navigation can be constructed. Navigation systems exemplify the following representational forms:

Modal - selection of either graphic or text to carry most meaning and be the governing way information is presented. If the user has a preference of either form of navigation, should this be available, or should one consistent mode be available to the user? The following icons from the Parliament Stack represent a purely graphic mode of navigation.

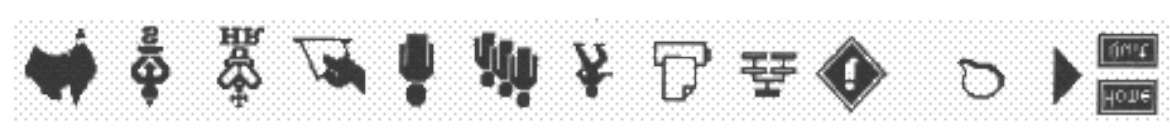

Hierarchical - moving through the content in terms of main idea to minor idea or visually clicking to see what is a small component of the larger. Most information has a subdivided or categorised structure. Each element of this structure of the information metaphor should be able to be used in conjunction with navigation around the overall metaphor or information environment. The information structure is often chunked to allow the hierarchical classification or structuring of the information to be accessible level by level as the detail is revealed. This type of navigation form is often strongly associated with a metaphor to represent the information and then what might be called sub-metaphors or maintenance of the metaphor is used to continue the analogy of the metaphor to more detailed information levels. This type of hierarchical information access maintains the overall metaphor of the information landscape, and yet can also allows the designer to represent the more detailed information in a variety of forms such as textual, video or audio format rather than maintaining the higher level metaphor. A simple hierarchical menu structure is shown below. 


\begin{tabular}{|l|l|l|}
\hline $\begin{array}{l}\text { Ac cess Data Bank } \\
\text { Create Test }\end{array}$ & $\begin{array}{l}\text { Input questions } \\
\text { from file } \\
\text { Promt Test }\end{array}$ & $\begin{array}{l}\text { Modify questions } \\
\text { Create/Modify Objectives }\end{array}$ \\
\cline { 2 - 2 } $\begin{array}{l}\text { Compile Results } \\
\text { Modify Test }\end{array}$ & $\begin{array}{l}\text { Print Objectives } \\
\text { Print Questions }\end{array}$ \\
\hline
\end{tabular}

Relational - how elements relate through objects such as stack maps. Stack maps are graphic representations of the information outline showing key nodes or decision points. When used, it should be ever present and accessible from all parts of the materials. A number of interactive multimedia packages make efficient and effective use of this navigation tool. The great advantage for the user is the availability of rapid access to location in the information landscape by cutting across the conceptual forms of representation of the information. The following example is again from the Parliament Stack.

\section{Stack Map of The Parliament Stack}

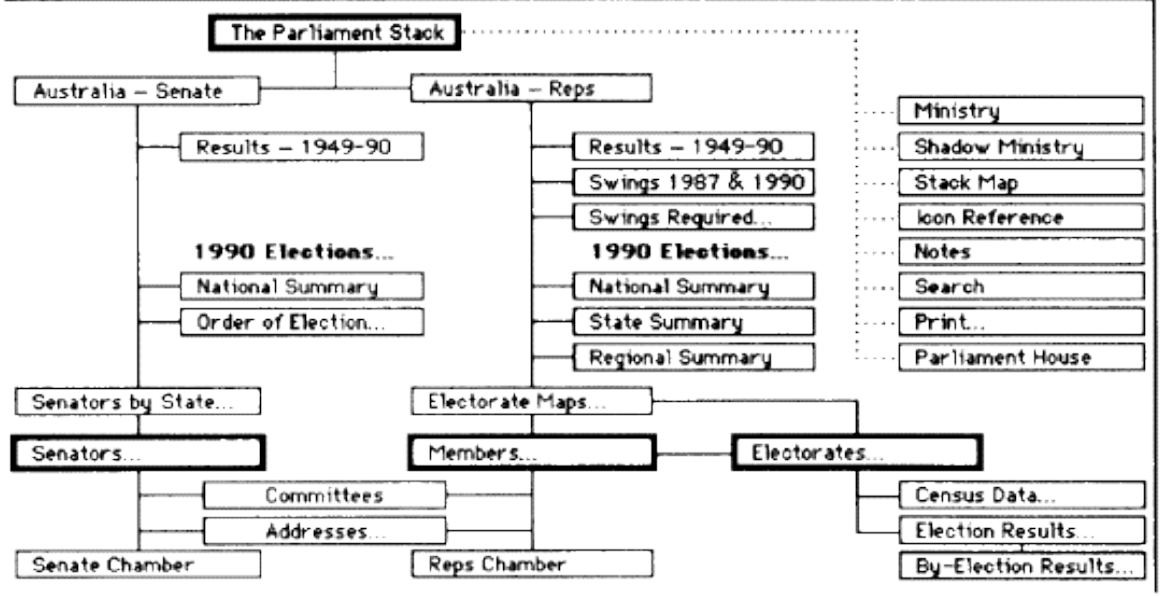

Sequential - moving through a database one card at a time either forward or backward. This type of navigation tends to be most appropriate at the lowest level information level or chunk and also is most appropriate when common elements need to be accessed. Elements such as where the user is in sequences and how to move in different directions are the main concern of this style of navigation (Grabinger, Dunlap \& Jonassen, 1992). The following palette represents such a simple sequential structure. 


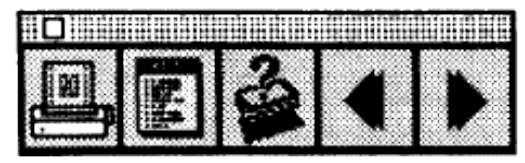

Geographical/Spatial - selecting parts of a whole by an inherent physical/geographic relationship. This approach might be exemplified region by using a map as the link between objects.

Conceptual - choosing between different key conceptual representations of the information landscape. Information access of a larger contextual nature can be embedded in learning packages in a variety of forms. The metaphor concept is commonly used for this type of information organisation system. There have been some quite good examples of this type of navigation implemented in current commercial packages. The following two examples are for an ecology simulation and a series of learning tools in an instructional sequence.
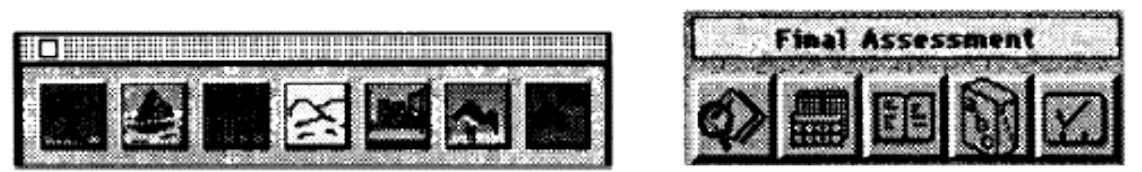

A number of representational forms can be used for navigation which have the potential to allow greater user control of information landscapes. There are a variety of strategies that can be incorporated into these navigation systems, but we know little about the effectiveness of the claims for clarity of access and development of user-centred learning outcomes.

These examples are drawn from a current research program that is investigating the range of navigation processes that can be applied to interactive multimedia. One implementation is discussed in the following pilot study.

\section{Navigational Forms - Pilot study}

In the first pilot study to investigate the metacognitive aspects of navigation systems a series of questions were considered (Murphy, 1992):

1. Do particular types of navigation suit particular instructional strategies?

2. What aspects of instructional design are dependent on navigation, and vice versa?

3. At what point should navigation be considered in instructional design?

4. Is the content related to the form of navigation?

5. Is there a minimum, maximum or ideal number of forms of navigation that a user can reasonably cope with? If so, how many? 
6. How do users' attitudes towards technology (specifically computer based learning systems) affect their approach to the materials, including their ability to use the materials and find their way?

7. What types and forms of help or explanation do users need to maximise their use of navigational aids?

The subjects of the study were student volunteers specialising in media production in areas other than sound (the instructional content was about sound). There were six women and four men, ranging in age from early twenties to early thirties. A computer-based course of study was designed, introducing the nature and elements of sound. The content covered the relationship between the physical and perceived quantities of sound (such as frequency and pitch). A hypermedia program was thought to be appropriate for helping the learner construct these relationships. From an instructional design point of view, the courseware was based on the Elaboration Theory model. Usually, the learner is restrained from moving to a deeper level until they have mastered or at least 'viewed' the next higher level. For this study, once the content was sequenced according to this model, a number of computerised forms of the instructional material were developed.

Each version of the courseware provided different forms of navigation through the content, allowing more or less learner control of the sequencing of the material. The levels of navigation examined were:

Sequential - one topic/level at a time, in a predetermined order, but allowing backtracking and learner control of time.

Hierarchical - allowing topic choice at each level (similar to a hierarchical menu system).

Relational - providing a map that relates elements, topics and contents, allowing (partial hypertext) the user to go to any level without restraint, but without browsing.

Metaphorical - allowing browsing and full access to all material and links, and also providing a navigational metaphor based (loosely) on the content: a CD player remote control panel.

Built into the courseware were software routines that recorded each page the user viewed, and the time spent on each page - the subject's learning path. The subject's answers to exercises were also recorded, for each attempt. When the subjects completed work with the course, these data were saved in a file, which was given a name incorporating the subject's identification code.

Prior to each observation, the subjects were given only minimal directions: the instructions on the use of the courseware was contained within the program itself. The subjects were not told of the specific nature of the study, only that the courseware was being trialed. They were advised that 
any problems they may have would be the fault of the courseware, and that they should not feel concerned about completing the content. However, they were asked to approach the task in the same way they would if they were in an actual learning situation. The subjects were also told that the researcher could not provide any help during the observation, but they were encouraged to ask questions and talk about problems so that these reactions could be recorded. Apart from time of day, the environment and situation were the same for all observations.

The dependent variable, user interaction with the content, is not easily defined or measured. Accessing a high percentage of the content may mean the user has made little use of the available navigational tools, simply going to each next page in sequence. On the other hand, if the user did not take a linear path through the content, yet accessed a high percentage of it, this should mean they have made good use of the available navigational aids - provided they have not aimlessly jumped around. Thus the need for the qualitative data to provide some indication of the intent of the user, not just the actions. Analysis of data for each subject is presented, followed by analysis of overall patterns.

User-path data was analysed in a similar fashion, using adjacency matrices (Bowers and Chia 1990). In the adjacency matrix, the intersection of the $\mathrm{i}$ th row and the $j$-th column represents page i. A transition from page $i$ to page $j$ would be represented by cell $(i, j)$. This representation provides one diagonal which represents forward transitions, from one page to the next; another diagonal which represents backward transitions, from one page to the previous one; and a third diagonal which represents attempts by the user to move to the current page. Anything outside these three diagonals represents a jump from one page to a non-adjacent page. The number of each of these types of transitions was calculated for each learner, as was the number of pages visited and the time spent on the important categories of pages: introduction/ content, help and navigational maps.

\section{Results}

The subjects generally showed positive attitudes towards computers, even though their experience and knowledge of computers was somewhat limited. None of the subjects had any knowledge of what comprised hypermedia or hypertext programs, although some had used computerbased tutorials of the kind supplied with many software packages. A summary of the important observation results is shown in Table 2.

The data reflect the highly individual responses to the courseware. The shortest observation was just over 5 minutes, with the subject (B) believing he had seen all the content. The longest observation was more than thirty minutes, while the shortest time to cover all material was 22 minutes 
(subject C). Subjects A, E and J in many ways exhibited some of the most widely differing responses to the courseware, yet they all have the same learning style. They are divergers, and would thus rely mainly on concrete experience and reflective observation. Their preferred learning modes are said to include lectures relating to real life, demonstrations, brainstorming, and discussion of ideas. Subject $J$ used the simplest navigation form, and it would have been interesting to see whether, if she had additional navigational tools available she would have taken such a highly linear path through the material. Once she had discovered that there were exercises embedded in the course, she began to take notes rather than go back and forth page by page if she needed to review material. In fact, she constructed her knowledge on paper in order to answer the questions. Still, in taking notes she did move back and forth a lot hence the high linear transitions / jumps ratio - much higher than Subject C, who also used the sequential form and covered $100 \%$ of the content.

Table 2: Selected observation data for each subject.

The Linear Transitions/Jumps Ratio is the ratio of all forward (next page) and backward (previous page) to jump (to non-adjacent page) transitions, from the learning path data automatically logged by the courseware.

\begin{tabular}{|c|l|l|c|c|c|c|c|c|c|c|}
\hline $\begin{array}{l}\text { Sub } \\
\text { ject }\end{array}$ & $\begin{array}{l}\text { Learning } \\
\text { style }\end{array}$ & $\begin{array}{c}\text { Navigat- } \\
\text { ional form }\end{array}$ & $\begin{array}{c}\text { Time } \\
\text { navi- } \\
\text { gating }\end{array}$ & $\begin{array}{c}\text { Pages } \\
\text { seen }\end{array}$ & $\begin{array}{c}\text { Cont- } \\
\text { ent } \\
\text { pages } \\
\text { seen }\end{array}$ & $\begin{array}{c}\text { Time } \\
\text { on } \\
\text { content } \\
\text { pages }\end{array}$ & $\begin{array}{c}\text { Time } \\
\text { on } \\
\text { ontro/ } \\
\text { help } \\
\text { pages }\end{array}$ & $\begin{array}{c}\text { Time } \\
\text { seeking } \\
\text { help from } \\
\text { others }\end{array}$ & $\begin{array}{c}\text { Use of } \\
\text { available } \\
\text { navig- } \\
\text { ation } \\
\text { methods }\end{array}$ & $\begin{array}{c}\text { Linear } \\
\text { transitions } \\
\text { / jumps } \\
\text { ratio }\end{array}$ \\
\hline A & Diverger & Relational & $34 \%$ & $33 \%$ & $36 \%$ & $67 \%$ & $10 \%$ & $19 \%$ & $33 \%$ & 0.25 \\
\hline B & $\begin{array}{l}\text { Accomm- } \\
\text { odator }\end{array}$ & $\begin{array}{l}\text { Hierar- } \\
\text { chial }\end{array}$ & $32 \%$ & $20 \%$ & $18 \%$ & $58 \%$ & $20 \%$ & $12 \%$ & $25 \%$ & 0.44 \\
\hline C & $\begin{array}{l}\text { Accomm- } \\
\text { odator }\end{array}$ & $\begin{array}{l}\text { Sequen- } \\
\text { tial }\end{array}$ & $14 \%$ & $89 \%$ & $100 \%$ & $93 \%$ & $5 \%$ & $6 \%$ & $50 \%$ & 16.17 \\
\hline D & $\begin{array}{l}\text { Accomm- } \\
\text { odator }\end{array}$ & Relational & $33 \%$ & $67 \%$ & $82 \%$ & $73 \%$ & $16 \%$ & $5 \%$ & $36 \%$ & 2 \\
\hline E & $\begin{array}{l}\text { Diverger } \\
\text { Relational }\end{array}$ & $24 \%$ & $69 \%$ & $93 \%$ & $85 \%$ & $7 \%$ & $6 \%$ & $43 \%$ & 1.42 \\
\hline F & $\begin{array}{l}\text { Assimil- } \\
\text { ator }\end{array}$ & $\begin{array}{l}\text { Metaph- } \\
\text { orical }\end{array}$ & $23 \%$ & $43 \%$ & $57 \%$ & $67 \%$ & $12 \%$ & $8 \%$ & $18 \%$ & 4 \\
\hline G & $\begin{array}{l}\text { Diverger } \\
\text { Relational }\end{array}$ & $46 \%$ & $51 \%$ & $61 \%$ & $60 \%$ & $16 \%$ & $15 \%$ & $56 \%$ & 1 \\
\hline H & $\begin{array}{l}\text { Accomm- } \\
\text { odator }\end{array}$ & $\begin{array}{l}\text { Hierar- } \\
\text { chial }\end{array}$ & $14 \%$ & $73 \%$ & $100 \%$ & $98 \%$ & $0 \%$ & $1 \%$ & $38 \%$ & 5.5 \\
\hline I & $\begin{array}{l}\text { Accomm- } \\
\text { odator }\end{array}$ & $\begin{array}{l}\text { Metaph- } \\
\text { orical }\end{array}$ & $25 \%$ & $53 \%$ & $82 \%$ & $90 \%$ & $6 \%$ & $10 \%$ & $12 \%$ & 12 \\
\hline J & $\begin{array}{l}\text { Diverger } \\
\text { Sequen- } \\
\text { tial }\end{array}$ & $21 \%$ & $89 \%$ & $100 \%$ & $94 \%$ & $4 \%$ & $11 \%$ & $50 \%$ & 72 \\
\hline
\end{tabular}

Subject A covered very little of the content, yet was without a doubt the most enthusiastic of all subjects about the courseware after using it for a short time. He discovered the links map fairly early, and then spent most of the rest of the time discovering how the courseware was structured rather than covering the content. He was excited about using a computer to learn, seeing it as a very positive alternative to traditional classroom teaching methods. 
The third diverger, subject $\mathrm{E}$, used more individual navigational aids than any other subject. This was largely due to his experience with interactive computer games, so that he was quickly able to grasp the operation and structure of the courseware. He covered $93 \%$ of the content, and yet did so in a very non-linear fashion - a linear transitions / jumps ratio of only 1.42. After the observation he commented that he expected the course to be longer, and was in fact surprised when he realised he had reached the end. Apart from this, he had no trouble finding his way through the material.

Subject B had the opposite experience. His was the shortest observation, because he decided very early on that he had covered all the material, even though in fact he covered only $18 \%$ of the content. His problem arose from a misconception of how the navigational aids worked, leading him to believe there were only five pages of content - one for each of the topic buttons. One reason he used only the topic buttons is that they were at the bottom of the screen, in the same position as the initial instructions on the very first page. Having read those instructions, he continued to focus on the same part of the screen. Subject B was one of the five accommodators, learners who rely largely on concrete experience and active experimentation. Their preferred modes of learning include people-based activities, simulations and games, discussions, small group projects and 'hands-on' learning. If these learners are to gain from computer-based courseware, interactivity would seem to be a must. Yet curiously, these subjects seemed accepting of what the computer offered them, three of the five proceeding through the material in a very linear fashion. In fact, subject I, with the most navigation options (the metaphorical form) used only $12 \%$ of those options and had a high linear transitions/ jumps ratio of 12. Of the five, only subject $D$ made any real use of the available navigation options, covering $82 \%$ of the content with a linear transitions/ jumps ratio of 2. But her exploration had as much to do with learning how to use the courseware as learning the actual content. She skipped the 'howto' material because she felt she didn't want to waste time. At one stage she commented that she found it difficult working through the material without objectives not realising that she had also skipped the material which provided objectives and context for the content. Her problem was not so much navigation as how to approach the learning situation itself. It would seem, then, that accommodators have difficulty with self-directed learning, even to the extent of accepting what the computer offers rather than making use of potential interactivity.

The one assimilator in this study, Subject F, expressed little interest in the content, but felt that the courseware would be more beneficial and enjoyable than hand-outs on the same subject matter. His lack of interest and stated tiredness resulted in a short observation (11 minutes), during which he covered only $57 \%$ of the content, in a fairly linear fashion. His most valuable contribution to the study was to highlight the difficulty 
getting an unmotivated learner to complete self-paced, self-directed learning - even with assimilators, for whom this is a preferred mode of learning.

One subject, G, initially waited for something to happen, rather than starting out herself (nothing does happen without the user's interaction). She spent quite a lot of time seeking help and also recorded the highest percentage time spent on navigating, while accessing only $61 \%$ of the content. This subject specialised in a visual study area, and found that the use of colour was an important navigational aid for her (each section of the course used a different background colour, with the same colours then being used on topic link buttons and the links map). Although colour is not generally thought to make any difference to learning gain, it seems it should be considered as one potential navigational aid, appropriate for some users.

Except for subject $\mathrm{H}$, all users spent a fairly large portion of their time seeking help. Subject $\mathrm{H}$ did not in fact make use of the introductory material on how to use the course, and quickly moved through the course. By missing out on the introductory material, however, she limited her navigation options, and so progressed in a very linear fashion (linear transitions/jumps ratio of 5.5). She also viewed all the content. and stated afterwards that she preferred not to jump around, particularly when the course was well structured. She did have some prior experience of computer-based software package tutorials, which tend to progress in a largely linear fashion. This would appear to have affected her view of how she might access the content, even when a number of options were available (in the hierarchical version of the courseware).

There was in fact a general reluctance to view the introductory material, with most only interested in the content itself. There appear to be a variety of reasons for this, including impatience. but also the feeling that they already knew how to use the courseware. The study has indicated that embedded help is not enough when users have no concept of what hypermedia offers in terms of allowing them to structure the knowledge in their own way.

A Student's t-test performed on pre-observation and post-observation content tests did not show any significant learning gain at alpha $=0.05$. For a one-tailed test with 9 degrees of freedom the critical value of $t$ is 1.833 , while the observed value was 1.103 . It must be remembered that the subjects each completed different proportions of the content and that the tests covered the whole of the content area. If only those subjects who completed more than two-thirds of the content are included in the t-test, the critical value of $t$ with 5 degrees of freedom is 2.015, and the observed $t$ is 2.445. In this case there is a significant difference between the pre- and post-observation scores. Of course the caution is that the sample size is 
very small, but the results are suggestive of one important relationship between navigation and learning outcome: if the navigation tools are such that the user is unable to access most of the content, there will not be any significant learning gain.

\section{Summary of the Pilot Study}

Sequencing of content has always been considered an important factor in any instructional design, especially for computer-based courses. However, some authors have suggested it may not be so crucial for hypermedia/hypertext materials, where the learner presumably takes control of the sequence, interacting in ways the designers did not plan (Hedberg \& Harper 1992b). In fact, in cases where the user does take control of their learning path, a structure imposed by the designers may be inappropriate. However, some designed sequence should be available for those learners who will not take this control (Clarke 1990).

It appears from this study that if the sequence and content are well constructed/users may be more inclined to take the 'easy' option, following a mostly linear path through the material. If this is not the best fit to the learner's preferred mode, long-term learning gain may be affected. The development of guides or agents as an interface and navigational aid may help in addressing the problems identified with providing appropriate help, match to learning styles, and sequencing (Oren et al 1990). Certainly, these are among the factors that researchers and instructional designers should be considering in their work on guides. They are also factors that human guides should consider when introducing students to hypermedia courseware.

\section{Conclusion}

People differ in the strategies they intuitively have available to them, in the degree to which they are aware of and monitor these strategies, and in the time they take to reflectively evaluate and revise strategy use. Metacognition is not seen here as something we need to measure, but something which can be enhanced to promote learning generally in the field of interactive multimedia. Strategies differ according to task requirements. Software developers and instructors need to think carefully through tasks and supply tools to facilitate the completion of the task as well as the monitoring of the process. It is easy as an expert to delegate a task which you feel has three simple steps, only to find out from frustrated feedback that those steps themselves required quite complex skills you now take for granted. Your schema has chunked much information in many levels and directions around that concept node (in hypermedia jargon). By providing with the task a set of strategies for approaching the task, you would be forced to analyse the task components and think 
realistically about what tools you supply to facilitate task completion. In reflecting on your own strategies, you would also gain from the process.

If the aim is for students to acquire a subject schema, problem-solving may not be an appropriate initial task style. Education goals have focused on higher order thinking, problem-solving and transfer. These levels of processing are almost impossible for anyone outside their knowledge domain, and not much easier for many within their knowledge domain. Strategy support, modelling of problem-solving and attention to dialogue can help. Hypermedia provides a wonderful means to construct and relate information, to repurpose and upgrade information, and to view as the experts do, an ever-increasing body of knowledge through multiple perspectives for a range of purposes. Recommended developments in performance support can be summarised simply as modelling of problemsolving and strategies, provision of integrated cognitive tools to facilitate, templates for self-monitoring of process, and dialogue. Cooperative work both in design and use of the designed materials should be the norm rather than the exception if feasible.

In this paper we have focussed upon the research issues associated with the design and provision of effective, and intuitive navigation systems and the importance of conceptual clarity in the quest for knowledge using navigation systems. The change in locus of control from instructor to learner raises a series of hypermedia issues about cognition, motivation and navigation which need to be explored. The variety of options available to instructional designers now need to be evaluated in the light of the various instructional paradigms so that clear guidelines for developers can be determined and made available. Only with detailed information about the user perceptions and use of navigation systems for interactive multimedia packages can we hope to effectively master the technology for improved learning outcomes.

\section{References}

Alexander, P. A., Schallert, D. L. \& Hare, V. C. (1991). Coming to Terms: How Researchers in Learning and Literacy Talk About Knowledge. Review of Educational Research, 61(3), 315-343.

Ambron, S. \& Hooper, K. (Eds.) (1990). Learning with Interactive Multimedia: Developing and Using Tools in Education. Washington: Microsoft Press.

Anstey, M. (1988). Helping Children Learn How to Learn. Australian Journal of Reading, 11(4), 269-277.

Bork, A. (1991). Computers and Educational Systems. Australian Educational Computing, September, 34-37.

Bowers, D. \& Chia, T. (1990). HyperCard in educational research: An introduction and case study. Educational Technology, 30(2), 19-24.

Bransford, J. D., Vye, N., Kinzer, C. \& Risko, V. (1990). Teaching thinking and content knowledge: Toward an integrated approach. In B. F. Jones 
\& L. Idol (eds.), Dimensions of Thinking and Cognitive Instruction, pp381413. Hillsdale, New Jersey: Lawrence Erlbaum Associates.

Clarke, J. (1990), Designing CAL programs to cater for different learning styles. In A. McDougall \& C. Dowling (eds), Computers in Education. North Holland: Elsevier Science Publishers.

England, E. (1985), Interactional analysis: The missing factor in computeraided learning design and evaluation. Educational Technology, 25(9), 24-28.

Eylon, B., \& Linn, M. C. (1988). Learning and Instruction: An Examination of Four Research Perspectives in Science Education. Review of Educational Research, 58(3), 251-301.

Grabinger, R. S., Dunlap, J. C., \& Jonassen, D. H. (1992). Sequential links. Performance and Instruction, 31(10), 46-49.

Grabowski, B. L., \& Curtis, B (1991). Information, Instruction and Learning: A Hypermedia perspective. Performance Improvement Quarterly, 4(3), 2-12.

Hedberg, J. G. \& Harper, B. M. (1991). Cognitive demands of navigation in interactive multimedia. Interactive Learning International, 7(3), 267-268.

Hedberg, J. G. \& Harper, B. M. (1992a). Creating interface metaphors for interactive multimedia. Proceedings of the International Interactive Multimedia Symposium, Perth, WA, January 27-31, 1992, pp 219-226. http:/ / www.ascilite.org.au/aset-archives/confs/iims / 1992/hedberg.html

Hedberg, J. G. \& Harper, B. M. (1992b). Navigation options in interactive multimedia. In J. Hedberg \& J. Steele (eds.), Educational Technology for the Clever Country: Selected papers from EdTech '92, Adelaide, Australia, 1-3 October, 1992. Belconnen, ACT: AJET Publications. http:/ / www.ascilite.org.au/ aset-archives/ confs/edtech92/hedberg.html

Hedberg, J. G. \& Perry, N. R. (19855). Human-computer interaction and CAI: A review and research prospectus. Australian Journal of Educational Technology, 1(1), 12-20. http: / / www.ascilite.org.au/ ajet/ ajet1/ hedberg1.html

Hedberg, J. G. (1989). The relationship between technology, and mathematics education: Implications for teacher education. In Department of Employment, Education and Training, Discipline Review of Teacher Education in Mathematics and Science. Volume 3. Canberra: Australian Government Publishing Service. pp 103-137.

Hooper, K. (1990). Introduction. In S. Ambron \& K. Hooper (Eds.), Learning with Interactive Multimedia: Developing and Using Tools in Education. Washington: Microsoft Press.

Jonassen, D. H. (1991a). Evaluating constructivist learning. Educational Technology, 31(9), 28-33.

Jonassen, D. H. (1991b). Hypertext as instructional design. Educational Technology Research and Development, 39(1), 83-92.

Lawrenz, F. (1990). Science Teaching Techniques Associated with Higher Order Thinking Skills. Journal of Research in Science Teaching, 27(9), 835847.

Martinez, M. E. \& Haertel, E. (1991). Components of interesting science experiments. Science Education, 75(4), 471-479. 
Merrill, M. D. (1991). Constructivism and Instructional Design. Educational Technology, 31(5), 45-53.

Merrill, M. D., Li, Z. \& Jones, M. K. (1990). The Second Generation Instructional Design Research Program. Educational Technology, 30(3), 26-31.

Molenda, M. (1991). A Philosophical Critique of the Claims of "Constructivism". Educational Technology, 31(9), 44-48.

Murphy, S. (1992). Navigation: How learners find their way through computer-based instructional materials. Research Report. Wollongong: Faculty of Education, University of Wollongong.

Oren, T., Salomon, G., Kreitman, D. \& Don, A. (1990). Guides: Characterizing the interface. In B. Laurel (Ed.), The Art of Humancomputer Interface Design. Reading, Massachusetts: Addison-Wesley, pp 367-381.

Osman, M. E. \& Hannafin, M. J. (1992). Metacognition research and theory: Analysis and implications for Instructional Design. Educational Technology Research and Development, 40(2), 83-99.

Paris, S. G., \& Winograd, P. (1990). How Metacognition Can Promote Academic Learning and Instruction. In B. F. Jones \& L. Idol (Eds.), Dimensions of Thinking and Cognitive Instruction, pp. 15-51. Hillsdale, New Jersey: Lawrence Erlbaum Associates.

Perkins, D. N. (1991a). Technology Meets Constructivism: Do They Make a Marriage? Educational Technology, 31(5), 18-23.

Perkins, D. N. ( $1991 \mathrm{~b})$. What Constructivism Demands of the Learner. Educational Technology, 31(9), 19-21.

Salomon, G., \& Perkins, D. N. (1989). Rocky Roads to Transfer: Rethinking Mechanisms of a Neglected Phenomenon. Educational Psychologist, 24, 111-142.

Squires, D. \& Millwood, R., (1988). The influence of new software environments on CAL development. Computers in Education, 12, 67-71.

Sweller, J. (1988). Cognitive Load During Problem Solving: Effects on Learning. Cognitive Science, 12, 257-285.

Winn, W. D. (1991). The Assumptions of Constructivism and Instructional Design. Educational Technology, 31(9), 38-40.

Authors: Associate Professor John Hedberg is coordinator of the Information Technology in Education and of Postgraduate Programs, Associate Professor Barry Harper is Director of the Interactive Multimedia Laboratory and Christine Brown is a Doctoral student. Their address is Faculty of Education, University of Wollongong, Northfields Avenue, Wollongong, NSW 2522, Australia or email J.Hedberg@uow.edu.au

Please cite as: Hedberg, J. G., Harper, B. and Brown, C. (1993). Reducing cognitive load in multimedia navigation. Australian Journal of Educational Technology, 9(2), 157-181.

http: / / www.ascilite.org.au / ajet / ajet9/ hedberg.html 